\title{
Caregiver Burden in Learning Disability
}

\author{
Archana Simon ${ }^{1}$, Veena Easvaradoss ${ }^{2}$
}

\section{ABSTRACT:}

Developmental Disorders interrupt normal development in childhood and involve significant handicaps, with onset before 18 years, which affect adaptive, self-help, cognitive and/or social skills. One of the most commonly occurring developmental disorders in normal school going children in India is Specific Learning Disability (3\% to 10\%, Arun et al.,2013). The essential feature of Learning Disabilities is the presence of average to above average intelligence with large discrepancies between their abilities and specific areas of difficulty (DSM IV-TR, 2000). Parents play a crucial role in facilitating and maintaining gains in children with developmental disorders. Managing developmental disorders in children affects various aspects of the wellbeing of parents- the primary caregivers. This study focuses on the Quality of Life and Parenting Stress among parents whose children have Learning Disabilities. One hundred parents whose children were diagnosed with Learning Disability were involved in this study. The tools used were the World Health Organization Quality of Life Questionnaire (1996) and the Parenting Stress Scale by Judy. O. Berry (1995). Comparison with 100 parents whose children were normal was also studied and significant results were obtained. Gender differences in the experience of Quality of Life and Parenting Stress among parents whose children were diagnosed with Learning Disability was also seen. The study also explored the relationship between the Quality of Life and Parenting Stress experienced by parents whose children have Learning Disability. The relationship between the Quality of Life and Parenting Stress experienced by parents whose children are normal was also studied. The results of this study highlight the importance of integrating parental counselling and psycho-education for the effective management of Specific Learning Disability.

\section{Keywords: Learning}

The term Learning Disability is used to describe a specific group of children, adolescents and adults who have problems in learning.

${ }^{1}$ CPsychol, AFBPsS (UK)Department of Social and Behavioral Sciences, Oman Medical College, Sohar, Sultanate of Oman

${ }^{2}$ Associate Professor and Head, Department of Psychology, Women's Christian College, Chennai, India 


\section{Caregiver Burden in Learning Disability}

Learning disorders are diagnosed when the individual's achievement on individually administered standardized tests in reading, mathematics or written expression is substantially below that expected for age, schooling and level of intelligence (Nakra, 1996). The learning problems significantly interfere with academic achievement or activities of daily living that require reading, mathematical or writing skills. The learning disabled child shows a discrepancy between achievement and intelligence.

The role of the family of the disabled child is vital. The family is thought to be the optimum environment for the development of disabled individuals. The addition of a disabled member usually results in substantial adjustments in the roles, norms, goals and communication patterns of the family. The level of acceptance of the disabled may vary from one family to the next. Frequently, the presence of a disabled child does precipitate a range of problems that may hinder the functioning and development of the family unit as well as individual members. Adjustment and problems are not static but change throughout the course of the family. Parents play the crucial role in facilitating and maintaining developmental gains in disabled children. The diagnosis of disability in a child is a traumatic event. Parental reactions to their child's disability are highly individualistic. The type and intensity of their response depends on how parents handle crisis situations in general, stability of the marital relationships and parental aspirations. Some of the common reactions include guilt, disappointment, shame, grief, anger and disbelief.

A child's growth and development depends heavily on the different aspects of his/her environment. Parents have an irreplaceable influence on their child's growing years. The Quality of Life and Stress experienced by parents in turn affects the psychological adjustment of the child. Also, rehabilitation programs usually focus only on the management of the child's difficulty. There is little or no emphasis on the parent, who constitutes an important part of the child's environment. Identifying and managing parental distress and other difficulties faced by them may help increase acceptance of the child's difficulty. Parental Quality of Life and Parenting Stress were explored to bring to light the various facets of parental wellbeing thus facilitating provision of a wholesome management plan for the child with Specific Learning Disability.

\section{METHODOLOGY}

Ex-post-facto research design was used in this study. The independent variables were the presence of Specific Learning Disability and Gender. The dependent variables were Quality of Life and Parenting Stress.

Selection of the sample was carried out using the method of purposive sampling. Group A was the control group consisting of 100 parents (50 fathers and 50 mothers) whose children were normal. These children did not exhibit characteristics of Specific Learning Disability or any other developmental disorder as determined by a screening intake questionnaire. They were also matched for age and gender with the children in the Experimental group. Group B was an experimental group consisting of 100 parents (50 fathers and 50 mothers) whose children have 
Specific Learning Disability. Parents bringing their children for the first consultation to a Pediatric hospital and who were not informed of their child's diagnosis were included in the sample. Parents whose children had the co-morbid condition of Attention Deficit Hyperactivity Disorder, disabling health conditions (such as epilepsy and asthma) and families where more than one member had a disability were excluded.

The tools used were the World Health Organization Quality of Life Questionnaire (WHOQOLBREF, 1996) and the Parenting Stress Scale by Berry (1995).

\section{RESULTS AND DISCUSSION}

Data were analysed using one-way ANOVA and Pearson coefficient of correlation.

Table 1 represents the mean, SD and Critical Ratio on the WHOQOL-BREF for parents of Groups A and B

\begin{tabular}{|l|l|l|l|l|}
\hline Groups & $\mathrm{N}$ & Mean & SD & CR \\
\hline Group A & 100 & 100.84 & 11.61 & 3.82 \\
\cline { 1 - 4 } Group B & 100 & 95.3 & 11.68 & \\
\hline
\end{tabular}

$* \mathrm{p}<0.01$ : Significant at the 0.01 level

Results indicate that there is a significant difference in the quality of life of parents whose children have Specific Learning Disability and parents whose children are normal. Parents whose children have Specific Learning Disability have significantly lower Quality of Life. The parental burden that resulted from developmental disorders is greater than the burden associated with other disorders (Angold, 1998). The child's symptomatology and impairment increases the level of burden experienced by parents who are the primary caregivers.

Another interesting observation was that there were no gender differences in the experience of caregiver burden in learning disability. Both fathers and mothers obtained low Quality of Life scores. The presence of Specific Learning Disability adversely affects many areas of child psychosocial functioning including academic, social and emotional adjustment resulting in lowered parental quality of life.

Table 2 represents the mean, SD and Critical Ratio on the Parental Stress Scale for parents of Groups A and B

\begin{tabular}{|l|l|l|l|l|}
\hline Groups & N & Mean & SD & CR \\
\hline Group A & 100 & 32.40 & 6.18 & \multirow{2}{*}{11.62} \\
\cline { 1 - 4 } Group B & 100 & 44.83 & 8.74 & \\
\hline
\end{tabular}

$*_{p}<0.01$ : Significant at the 0.01 level 
Results indicate that parents whose children have Specific Learning Disability experience higher stress when compared to parents whose children are normal. The increased demands of the child with regard to parenting roles may be attributed to higher parental stress. Also, as Turnbull et al., (1993) reported, a major source of stress for parents involved their efforts to obtain appropriate educational services. Mothers and fathers experience similar levels of stress. No gender differences exist in the level of parental stress experienced by the experimental and control groups. Traditionally women are the primary caregivers for their children. Fathers' participation in childcare activities may be increasing (Snarey, 1993), indicating similar levels of stress with regard to parenting roles.

Table 3 represents the mean and SD on the WHOQOL-BREF and the Parental Stress Scale and the Coefficient of Correlation between them as experienced by Group B

\begin{tabular}{|l|l|l|l|l|}
\hline Group B & N & Mean & SD & r \\
\hline Quality of Life & 100 & 95.30 & 11.68 & -0.38 \\
\cline { 1 - 4 } Parental Stress & 100 & 44.83 & 8.74 & \\
\hline
\end{tabular}

$* \mathrm{p}<0.01$ : Significant at the 0.01 level

Results indicate that a significant negative relationship exists in the quality of life and stress experienced by parents whose children have Specific Learning Disability. As the level of parental stress increases, the quality of life of life decreases. This finding correlates with the Cognitive Model of Stress as proposed by Lazarus and Folkman in 1984. They define stress as 'a particular relationship between the person and the environment that is appraised by the person as taxing or exceeding his or her resources and endangering his or her wellbeing'. They have classified event perception as being either irrelevant or having no implications for the person's wellbeing, benign positive if it preserves the person's wellbeing and stressful when the person's wellbeing is affected. Therefore, parents whose children have Specific Learning Disability perceive their child's disability as stressful and thus experience lowered quality of life. No gender differences exist.

\section{CONCLUSIONS}

Parents whose children have Specific Learning Disability experience low quality of life and high parenting stress. This study highlights that while managing Specific Learning Disability, parental aspects also need to be addressed to provide wholesome management for the child. Addressing and managing parental stress will also improve quality of life experienced. Both fathers and mothers of children with Specific Learning Disability should be given assistance to improve their wellbeing. A parental counselling module incorporated into the management program for Specific Learning Disability will be beneficial. Sessions addressing parental anxiety, depression, self-esteem, guilt or self-blame in addition to psycho-education focused on empowering parents to effectively manage their child with Learning Disability will be beneficial. Individualized parental counselling will increase parental acceptance of the child's difficulty, reduce parental stress and anxiety, enhance a positive approach while dealing with their child with Learning 
Disability and help parents recognize personal strengths to aid their child's progress. This will play an important part in improving the quality of life of the parent and reducing parental stress, thus enhancing parental wellbeing. Improvement in parental wellbeing will in turn foster healthy interactions with their children who have Learning Disability. As a result, a healthy, stimulating environment created will facilitate progress of children with Learning Disability . Integration of Parental and Caregiver counselling in paediatric settings will enhance effective management of Learning Disability and other developmental disorders.

\section{REFERENCES}

1. American Psychiatric Association. (2000). Diagnostic and Statistical Manual of Mental Disorders.(Edn.4).

2. Angold (1998).Perceived parental burden and service use for child and adolescent psychiatric disorders. American Journal of Public Health,88,7580.

3. Arun P et al., (2013). Prevalence of specific developmental disorder of scholastic skill in school students in India. Indian Journal Of Medical Research,138(1) 89-98

4. DSM-IV-TR workgroup. The Diagnostic and Statistical Manual of Mental Disorders, Fourth Edition, Text Revision. Washington, DC: American Psychiatric Association.

5. Hastings,R.P.(2000). Parental stress and behaviour problems of children with developmental disability. Journal of Intellectual and DevelopDisability,27, 149-160.

6. Kirk, S.A., \&Crallagher, L. (1979). Educating Exceptional Children. ( $3^{\text {rd }}$ edn.). Boston. Houghton Mifflin Company

7. Nakra, O. (1996). Children and Learning Difficulties. New Delhi: Allied Publishers Limited

8. Snarey, J. (1993). How fathers care for the next generation: A four decade study. Cambridge, MA: Harvard University Press

9. Tanner,O. (1976). Stress. New York: Time Life Books.

10. Turnbull A ET AL., (1993). Cognitive coping, families and disability. Baltimore, MD: Paul H Brookes 